Lexis Vol. XLII (1) 2018: 123-152

\title{
Kirchnerismo y discurso fundacional: los editoriales de la agrupación juvenil La Cámpora
}

\author{
Rocío Flax \\ Universidad de Buenos Aires / CONICET
}

\begin{abstract}
RESUMEN
El presente trabajo se inscribe en una investigación que busca comprender, desde una perspectiva lingüístico-discursiva, el surgimiento y la consolidación de la agrupación política argentina denominada La Cámpora. Esta agrupación fue organizada desde el gobierno de Néstor Kirchner y, actualmente, se encuentra alineada con la presidenta Cristina Fernández. En esta oportunidad, se examina la forma en que la agrupación juvenil se posiciona como discurso fundacional, presentando al kirchnerismo como una ruptura total con un pasado presentado como desastroso para los argentinos. Para ello, se tendrán en cuenta dos ejes de análisis: en primer lugar, la construcción de enemigos y, en segundo lugar, la utilización de sintagmas temporales y espaciales dislocados hacia la izquierda de la cláusula como forma de reforzar la diferencia con el pasado y la excepcionalidad del presente.
\end{abstract}

Palabras clave: Análisis del discurso, pragmática, discurso político, discurso fundacional 


\section{AbSTRACT}

This work is part of a research project that seeks to understand, from a linguistic-discursive perspective, the creation and consolidation of the Argentine political group called La Cámpora. This group was organized by former president Nestor Kirchner and nowadays follows the leadership of president Cristina Fernandez. This time, we examine the way the political group positioned itself as foundational discourse, presenting Kirchner as a complete break with a past presented as disastrous for the country. For this pourpose we will consider two lines of analysis: first, the construction of enemies and, secondly, the use of temporal and spatial expressions dislocated to the left of the clause as a way to reiforce the difference with the past and the uniqueness of the present.

Keywords: Discourse analysis, pragmatics, political discourse, foundational discourse

\section{Introducción}

El presente trabajo se inscribe en un proyecto de investigación que busca comprender, desde una perspectiva lingüístico-discursiva, la especificidad de la construcción, el desarrollo y el afianzamiento de la agrupación política juvenil argentina denominada La Cámpora.

Esta agrupación comenzó a organizarse a finales del año 2006, desde el propio gobierno de Néstor Kirchner, quien consideró necesaria la organización de una juventud militante a nivel nacional. Las primeras apariciones públicas de La Cámpora, sin embargo, datan recién del año 2008, al igual que la difusión de sus discursos. Se trata de la organización kirchnerista con mayor exposición mediática y se encuentra fuertemente ligada a las figuras de Néstor Kirchner, presidente de la Nación entre los años 2003 y 2007, y Cristina Fernández de Kirchner, presidenta desde el 2007 hasta el 2015. Incluso, el hijo de ambos presidentes, Máximo Kirchner, se encuentra entre sus principales dirigentes desde los orígenes mismos de la agrupación. Además, algunos de sus miembros más destacados ocuparon diversos cargos durante los gobiernos de Cristina Fernández, tanto en el poder ejecutivo como en el legislativo. 
En este artículo, se examina la forma en que la agrupación juvenil se posiciona como discurso fundacional, presentando al kirchnerismo como una ruptura total con un pasado presentado como desastroso para los argentinos. Para ello, se tendrán en cuenta dos ejes de análisis. En primer lugar, uno de los ejes es la construcción de adversarios en términos de enemigos en la totalidad de los editoriales que componen el corpus a través de la activación del campo conceptual bélico y de referencias metafóricas al uso de violencia. El segundo eje de análisis es la utilización de sintagmas temporales y espaciales dislocados hacia la izquierda de la cláusula como forma de reforzar la diferencia con el pasado y la excepcionalidad del momento presente. Para la consecución del análisis se utiliza, como marco teórico, la oposición entre discurso fundador y discurso fundacional propuesta por el análisis del discurso (Orlandi 1993; Zoppi Fontana 1993). El corpus utilizado está compuesto por treinta y un discursos pertenecientes a la sección editorial de la página web de la agrupación juvenil, entre los años 2008 y 2011.

En el apartado número dos, desarrollaremos el marco teórico, mostrando las particularidades del discurso fundacional y sus diferencias con el discurso fundador. En la sección tres, ampliaremos las características específicas de la agrupación La Cámpora y su historia. Luego, pasaremos al análisis de la construcción de adversarios, en un primer momento, y de las estructuras temporales y espaciales reforzadoras, en un segundo momento. Por último, presentaremos las conclusiones del análisis.

\section{El discurso fundacional}

Eni Orlandi (1993) postula la existencia de un tipo particular de discurso denominado "fundador". Su especificidad consiste en instaurar una discursividad diferente, en ser el primer eslabón de una formación discursiva, generalmente vinculada con la necesidad de creación de una identidad nueva para determinados actores sociales. Es por ello que algunos autores relacionaron el discurso fundador con aquel que instituye la identidad nacional (Guimarães 1993; 
Nunes 1993). Según Orlandi, para que un discurso sea considerado fundador, debe presentar un requisito interdiscursivo, con prescindencia de las representaciones o contenidos que vehiculice. Su particularidad radica en los efectos que produce, es decir, en su vínculo con la historicidad: debe ser considerado fundador y tomado como tal por discursos posteriores.

Así, el discurso fundador debe, en primer lugar, generar una ruptura con un pasado $-\mathrm{o}$, al menos, su reinterpretación- para poder instaurar un nuevo orden de sentidos (Orlandi 1993). Lo que hace a un discurso fundador es, entonces, la constitución de una nueva tradición, ya sea revalorizando lo anterior o construyendo una memoria diferente. Y, en segundo lugar, debe crear una filiación discursiva, una tradición nueva de sentidos que se proyecta a otros discursos. Esta filiación se constituye tanto por los vínculos que establece con el pasado como con el futuro: la misma ruptura con un pasado crea una filiación de memoria con una tradición de sentidos y establece un nuevo lugar de significación. Entonces, el discurso fundador instala las condiciones de formación de otros, construyendo una región de significados que configura un proceso de identificación para una cultura, una etnia o una nacionalidad:

O sentido anterior é desautorizado. Instala-se outra 'tradição' de sentidos que produz os outros sentidos nesse lugar. Instala-se uma nova 'filiação'. Esse dizer irrompe no processo significativo de tal modo que pelo seu próprio surgir produz sua 'memória' (Orlandi 1993: 13).

En contraposición a la noción de discurso fundador, Zoppi Fontana (1993) plantea la existencia de otro tipo de discurso: el fundacional. Los discursos fundacionales incluyen dentro de sus representaciones sociales y de su posición de enunciación el mismo gesto fundador. Es decir que no solo a posteriori —o, quizás, simplemente no-funcionan como una bisagra entre dos formaciones discursivas, sino que así se presentan en su misma estructura. Este sería el caso del género épico, por ejemplo, cuyo objetivo es establecer los orígenes reales o ficticios de un país o una comunidad, la 
identidad de un país o pueblo en nacimiento y, por lo tanto, debe incluir referencias a una ruptura con el pasado y la instauración de un orden nuevo.

En otras palabras, son fundacionales aquellos discursos que postulan esa ruptura con un pasado, que se autodefinen como creadores de una nueva identidad y una nueva discursividad, aun si no poseen los efectos que se postulan para el discurso fundador. Por ello, nos sirve la distinción que Zoppi Fontana establece entre discurso fundador y discurso fundacional. El discurso fundador genera, como ya vimos, una nueva memoria discursiva; el discurso fundacional no necesariamente lo hace. El rasgo principal de este último es que se construye como fundador a través de recursos que pueden ser rastreados en distintos niveles de discurso: sintaxis, semántica, enunciación, etc. Se estructura a partir de una ruptura con un pasado o de su relectura y de la construcción de un orden nuevo. No necesita ser iniciador de una identidad nacional ni ser reconocido por otros discursos como el "primero", es decir, no requiere del reconocimiento a posteriori, ni que se cumplan sus pretendidos efectos de instauración de una formación discursiva nueva.

Por otra parte, un discurso fundacional no requiere circunstancias históricas excepcionales, como sería el caso de un discurso para constituirse como fundador de una identidad nacional o comunitaria. No hace falta que su contexto de producción esté vinculado con el surgimiento de nuevas naciones, de un retorno a la democracia o de alguna coyuntura que exija la construcción discursiva de una nueva identidad. Simplemente, se trata de un discurso que plantea un quiebre histórico y el surgimiento de algo nuevo.

Siguiendo a Charaudeau (2009), el discurso fundacional se compone de tres momentos discursivos: 1) probar que la sociedad se encuentra en una situación social juzgada desastrosa y que el ciudadano es la primera víctima, 2) determinar la fuente del mal y su responsable, 3) anunciar finalmente qué solución puede ser aportada y quién puede ser su portador. En este tipo de discursos se escenifica lo siguiente: 1) una descripción catastrófica de la situación social de la que es víctima el pueblo; 2) una denuncia de los 
culpables, entre los cuales se encuentra la clase política, las élites aisladas del pueblo, las instituciones que han perdido toda autoridad y la burocracia fuente de todos los males; 3 ) la exaltación de los valores y 4) la aparición de un hombre/mujer providencial, capaz de romper con el pasado y convertirse en el salvador de la sociedad.

\subsection{La épica}

Consideramos a la épica como una forma de discurso fundacional propio de la Antigüedad y la Edad Media. Resulta interesante tener en cuenta sus características, ya que muchos actores políticos recurren a recursos propios de este género - como el vocabulario propio de las batallas y la construcción de héroes y hazañas- para la conformación de su identidad.

Siguiendo la definición de Conte (1986), el discurso épico tiene como fin legitimar acciones consideradas heroicas. El código épico es aquel mediante el cual una comunidad reorganiza sus propias experiencias históricas dotándolas de sentido con miras a constituir un sistema ejemplar. Es una fuente o reservorio de valores estructurales, representados concretamente por las acciones de los héroes. Se trata de un tipo de articulación cuyo objeto consiste en la organización literaria y narrativa de los valores culturales colectivos. Según Paquette (1988), cada epopeya —y esta es su singularidadpuede considerarse como el texto fundador de una comunidad cultural. La epopeya, entonces, más que un relato sobre las fundaciones históricas de una cultura, es ella misma fundadora de esa cultura; su intención y su destino como texto se confunden con el desarrollo de la comunidad que la epopeya funda, en cierto modo, simbólicamente. En este sentido, ya Menéndez Pidal $(1934,1945)$ afirmaba que la epopeya no es pura y simplemente un poema que toma prestado su tema de la historia, es un poema que realiza la misión político-cultural reservada a la historia.

Paquette plantea que el epos es, la mayoría de las veces, la historia de una derrota o, por lo menos, de un deshonor pasajero cuya ascensión a los extremos es la consecuencia última y necesaria. Así, 
la epopeya emite un discurso que podría decir lo siguiente: “este territorio nos pertenece. Él posee un valor absoluto. Quienquiera que, desde el exterior, penetre en él como un enemigo o cometa en él un acto reprensible es pasible de un castigo no menos absoluto: el aniquilamiento".

Percibida en todo momento de la historia de una cultura como su texto fundador, la epopeya es la forma simbólico-literaria correspondiente a la fase de territorialización de una comunidad lingüística. La territorialización refleja una sociedad decididamente guerrera: la ocupación y defensa de un territorio se definen, en principio y ante todo, como operación militar. Esta es la razón de por qué el periodo épico de una sociedad está universalmente asociado con la edad de los héroes. Además, dado que todo relato está constitutivamente fundado sobre y por una tensión (no se cuenta la historia de gente feliz y sin problemas), el proyecto narrativo de la epopeya encuentra en el acto heroico-guerrero el modelo consumado de esta tensión. Así, la guerra no es el tema de la epopeya solamente porque actúa como el reflejo de una sociedad guerrera, sino también porque se ofrece al acto narrativo como la tensión por excelencia. La guerra, como estructura de conflicto, da lugar no solo a numerosos tipos de "relatos" (crónicas, epitafios, etc.), sino también, y por sobre todo, a la narratividad misma.

La epopeya presenta dos principios que, de alguna manera, constituyen fuerzas absolutas e irreductibles (pueblos, religiones, regímenes). En este nivel, bajo las figuras más diversas, se ubica la gran polarización característica del universo épico reflejo de la fase de territorialización de una comunidad. Aquí, la epopeya recupera la operación de delimitación del territorio (real, proyectado o simbólico), que reside en la definición del Otro absoluto como enemigo y, al mismo tiempo, en la composición de la identidad (etimológicamente "vuelta de lo mismo" del sí mismo o, dicho de otra manera, del nosotros) (Paquette 1988; Campbell [1949] 1972).

Por último, plantea Paquette, en toda epopeya hay una crisis que sobreviene en el seno de la sociedad de la cual el relato épico tiene como misión hacerse portavoz. Esta crisis es el reflejo de la 
violencia inherente a toda sociedad. Ella se expresa, según el caso, por un tipo de movimiento de humor (traición, odio, cólera) sin un origen, inexplicable, "problemático" porque opone a "los hermanos de armas” de una misma comunidad. Es el pacto y la justificación de la violencia intracomunitaria. En este nivel, se encuentra hasta cierto punto valorizada la marca creadora de la sociedad que sacará de allí mismo, en el desarrollo ulterior de su cultura, su fascinación por el texto fundador.

\section{La Cámpora}

La idea de una agrupación juvenil propiamente kirchnerista comenzó a gestarse con la llegada del presidente Néstor Kirchner al poder en el año 2003. Sin embargo, recién a finales del año 2006 se logra reunir un conjunto de dirigentes jóvenes que comienzan a darle forma a La Cámpora. Ya para el año 2008, los miembros de esta agrupación hacen sus primeras apariciones públicas en marchas en apoyo al gobierno y son cubiertos por algunos diarios de tirada nacional. La irrupción masiva de este movimiento en la escena pública coincide con la muerte de Kirchner, en octubre del 2010, durante la presidencia de Cristina Fernández. Los jóvenes, en general, tuvieron una visibilidad muy considerable en el velorio del expresidente, pero los medios masivos de comunicación - tanto los gráficos como los audiovisuales - recalcaron el particular entusiasmo de un sector de la juventud kirchnerista: La Cámpora.

A partir de entonces y hasta fines del año 2015, sus dirigentes ocuparon puestos dentro del poder ejecutivo y en empresas nacionales y, en la actualidad, mantienen cargos de diputados tanto nacionales como provinciales o de la Ciudad de Buenos Aires. Si bien se definen como peronistas, constituyen un grupo diferenciado de otros sectores del peronismo tradicional y se encuentran fuertemente vinculados con las figuras de los presidentes Néstor Kirchner y Cristina Fernández, de quienes se presentan como sus posibles herederos políticos. 


\section{Análisis del corpus}

\subsection{La construcción de enemigos}

En trabajos anteriores (Flax 2014; 2016), mostramos cómo La Cámpora despliega en los editoriales de su página web dos polos diferenciados que corresponden, según el caso, a temporalidades distintas o a diferentes actores sociales actuales. Esta polarización se encuentra presente en todos los discursos que conforman el corpus de la investigación y se corresponde con la construcción de adversarios pasados o actuales a través de dos tipos de estructura:

1. En sincronía: kirchnerismo vs. oposición.

2. En diacronía: antes del 2003 vs. después del 2003 (momento en que Kirchner asume la presidencia).

Mientras que en algunos discursos se conmemoran eventos pasados (por ejemplo, el aniversario de la vuelta del expresidente Juan Domingo Perón ${ }^{1}$ a la Argentina en 1972, tras dieciocho años de exilio, la asunción de Héctor Cámpora a la presidencia en 1973 o la victoria electoral de Néstor Kirchner en el 2003), otras veces se defienden medidas tomadas por el gobierno kirchnerista o se atacan las decisiones, declaraciones o acciones del adversario político construido como un enemigo que representa una amenaza para los logros obtenidos — según las afirmaciones de La Cámpora- por el gobierno kirchnerista. Usualmente, el enemigo aparece como un tercero discursivo, pero en algunos casos es el destinatario explícito del editorial, lo cual eleva el nivel de confrontación, al interpelarlo directamente a través de la segunda persona gramatical.

En cualquiera de los casos, en los editoriales de La Cámpora, siempre aparece explícitamente la figura del otro, ya sea un opositor contemporáneo, uno referido al pasado reciente (el liberalismo de los años 90, por ejemplo), o referido a un tiempo histórico, como en el caso en que el otro está constituido por los españoles a los que

\footnotetext{
Juan Domingo Perón fue presidente de la República Argentina entre los años 1946 a 1955, cuando fue derrocado por un golpe militar. A partir de entonces hasta el año 1972, no pudo retornar al país y el peronismo estuvo prohibido como partido político.
} 
se opondrá José de San Martín. ${ }^{2}$ La estructura construida a partir de antagonismos (la patria vs. los organismos internacionales, San Martín vs. los colonizadores, el kirchnerismo vs. la oposición, el gobierno kirchnerista vs. los gobiernos anteriores, Perón vs. los antipatria, etc.) sirve para definir la identidad propia a partir del enfrentamiento. Es decir, la identidad se construye a partir del ataque a un otro construido como un enemigo y de la superioridad moral del kirchnerismo - y, en consecuencia, de La Cámpora que resulta de esa comparación (además del mérito propio que presupone compararse con figuras como San Martín; otras como Perón o el gobernador de Buenos Aires Juan Manuel de Rosas ${ }^{3}$ tienen un estatus más polémico dentro de la sociedad argentina).

A continuación, presentamos una tabla donde se puede observar la distribución de los enemigos construidos a lo largo de los editoriales que componen el corpus de investigación y de los ejes propuestos (sincrónico y diacrónico). Además, especifica si se trata de enemigos políticos, si hacen referencia a otros sectores como las empresas de medios de comunicación o los productores agropecuarios y si se encuentran nombrados de manera explícita y particularizada o no.

2 Por supuesto, cuando en la oposición no aparece el kirchnerismo se lo asimila al polo que representa las virtudes positivas. En este caso, a José de San Martín, general y héroe de la independencia de Argentina, Chile y Perú.

3 Juan Manuel de Rosas (1793-1877) fue un político y militar que gobernó la Provincia de Buenos Aires por casi dos décadas. Principal caudillo del país y cabeza del bando Federal durante las guerras civiles, alrededor de su figura se configuran distintas corrientes historiográficas en la Argentina. 


\section{Tabla 1. Construcción de enemigos en los editoriales de La Cámpora entre los años 2008 y 2011}

\begin{tabular}{lll}
\hline Editorial Eje sincrónico & Eje diacrónico
\end{tabular}

17 de noviembre $\mathrm{X}$

de 2008

Gobiernos militares de las

20 de noviembre Las AFJP

décadas del 50 al 70

de 2008

Los españoles de la

colonia, franceses e

ingleses (Batalla de la

Vuelta de Obligado, 1845)

14 de marzo de La oposición política y los medios

$\mathrm{X}$ 2009

20 de marzo de La cámara patronal (campo), Elisa 2009

Carrió. Referencia a periodistas

Años 90 (como metonimia de los gobiernos neoliberales de esa década)

5 de abril 2009 Discurso mediático (particulariza al $\mathrm{X}$ diario Clarín), oposición política en general

7 de abril de

Diario Clarín (monopolios mediáticos

$\mathrm{X}$ 2009 en general), miembros del partido Unión Cívica Radical (UCR), sector del campo, Hilda Duhalde (política opositora).

13 de abril de 2009

15 de abril de 2009

22 de abril de 2009

1 de mayo de 2009

25 de mayo de $\mathrm{X}$ 2009

18 de junio d 2009

23 de junio de 2009

9 de julio de 2009 $\mathrm{X}$
Felipe Solá y Mauricio Macri, la oposición política en general ("los demócratas representantes de las cámaras patronales sojeras”), discurso mediático

Pseudoprogresistas, Gobierno de la ciudad de Buenos Aires, la derecha política

\section{Diario Clarín}

“Operativo mediático" (monopolios de comunicación), "todos los enemigos de la ciudadanía decente”

Los medios de comunicación

$\mathrm{X}$ Francisco De Narváez, Gabriela Michetti, Elisa Carrió, Fernando Solanas, Alfonso Prat Gay), medios de comunicación, monopolios agropecuarios (Alfredo de Angeli)

$\mathrm{X}$

$\mathrm{X}$
La oposición política (Mauricio Macri, X

"Durante décadas" (Entre esos nombran a Felipe Solá y otros políticos argentinos)

$\mathrm{X}$

La Argentina anterior 


Editorial Eje sincrónico Eje diacrónico

14 de agosto de Sector del campo (Hugo Biolcati,

$\mathrm{X}$ 2009

Alfredo de Angeli), medios de comunicación (particulariza al diario Clarín), oposición política (Martín Buzzi, Julio Cobos)

21 de agosto de $\mathrm{X}$

2009

"Lo anterior"

1 de octubre de Oposición política, medios oligopólicos $\mathrm{X}$ 2009 de comunicación

26 de octubre de Los dueños de los medios de 2009 comunicación

28 de diciembre Medios de comunicación, oposición de 2009 política

Los medios (cómplices de las dictaduras y el neoliberalismo)

4 de marzo de Francisco De Narváez, UCR, diario X $2010 \quad$ Clarín.

12 de mayo de Martín Redrado, Julio Cobos y otros 2010 que apoyaron a Redrado (Medios de comunicación, UTE, jueces de la última dictadura militar)

19 de junio de Policía local de la ciudad de San Carlos 2010 de Bariloche

29 de julio de Medios de comunicación, pseudoprogesismo (Claudio Lozano, UCR, Partido Justicialista Disidente)

12 de septiembre Medios de comunicación, la oposición de $2010 \quad$ política

30 de septiembre UCR, PJ Disidente (quieren de 2010 reimplementar el modelo neoliberal)

Modelo neoliberal

(década del 90)

2 de noviembre Concentración mediática y oposición de 2010 política

27 de noviembre "Análisis periodísticos”, "grupos de de 2010 poder”

11 de febrero de Los que quieren volver al pasado 2011

11 de marzo de Dirigentes actuales con "peronitis 2011 selectiva”

Gobiernos anteriores

X

$\mathrm{X}$

Gobiernos anteriores (en particular década del 90)

Neoliberalismo

Presidencia Carlos Saúl Menem, dirigentes políticos anteriores

28 de mayo de Fríos de corazón y secos de mente (no 2011 queda muy en claro a quiénes refiere)

4 de julio de Analistas políticos y periodistas de 2011 Clarín, La Nación y Perfil

Analistas políticos y periodistas 
A partir de la tabla 1, observamos que no se trata solamente de otros políticos con quienes se compite, por ejemplo, en una campaña electoral, sino que el adversario es constituido por diferentes sectores de la sociedad, en particular por poderes económicos como el agropecuario o las empresas de multimedios, pero también por actores sociales como es el caso de los periodistas o la clase media "pseudoprogresista". También aparecen oponentes internacionales, como los organismos de crédito. También advertimos una prevalencia de los enemigos actuales con respecto a los enemigos pasados. En efecto, de treinta y un editoriales, veintisiete construyen un opositor que coexiste con el kirchnerismo y solo trece presentan un adversario anterior a la llegada de Kirchner al gobierno. Mientras que el enemigo que remite al pasado supone que ya fue derrotado, el que persiste en el momento de enunciación implica una amenaza constante a los logros de los gobiernos kirchneristas. Los adversarios sincrónicos se constituyen como tales por ser reminiscencias del pasado o intentar reimponer la situación conceptualizada como desastrosa, pero ya superada:

Por eso, cada vez que el pasado atine a ofrecerse como banal solución de problemas de alta complejidad como los que siempre ha encarado este Proyecto... (11.02.2011a)

No debemos olvidar que frases como estas llevaron a la Argentina en el pasado a la peor dictadura, dejando no sólo una generación desaparecida sino un país hipotecado y sin capacidad de reacción. (20.03.2009b)

En los 90 nos sacaban el trabajo, la educación y nos daban palos y represión. Ahora quieren volver a hacer lo mismo. (30.09.2010f)

Los enemigos pasados hacen referencia tanto a quienes fueron derrotados por el kirchnerismo como a aquellos que pertenecían a otros ciclos dentro de las refundaciones del país: los españoles, los franceses e ingleses que intentaron invadir el territorio argentino en el siglo XIX, los golpes de Estado de 1955 y de 1976.

4 Todas las referencias corresponden a las editoriales incluidas en la bibliografía final. 
Coincidimos con los autores que postulan una sobredimensión de la función adversativa en el discurso kirchnerista (Raiter 2009, 2013; Dagatti 2013). Si bien se trata de un elemento característico del discurso político, adquiere niveles superlativos (Balsa 2013) dentro del movimiento político en cuestión. Además, la construcción de un adversario político no significa, necesariamente, construirlo en términos de enemigo (ver tabla 2). En el discurso político, los destinatarios adversos suelen ser presentados de formas más difusas, mientras que aquí se los nombra y ataca explícitamente, constituyendo en algunos casos el destinatario directo (segunda personal gramatical). En el caso de La Cámpora, la caracterización del otro como un enemigo se realiza a través de la activación del campo conceptual bélico y de la asociación del adversario político con diferentes formas de violencia. A continuación, presentamos una selección de editoriales de la agrupación juvenil que muestran las alusiones al campo de la guerra y la violencia que se encuentran presentes en todos los discursos que integran nuestro corpus.

Tabla 2. Campos conceptuales guerra y violencia en general

Fragmento

Discurso

La lucha es permanente (cláusula 3)

Editorial del

Hoy más que nunca tenemos que hacer frente a nuevos desafíos y dificultades pero con las convicciones de siempre (cláusula 4) 13 de abril de 2009

Como tampoco es casualidad que aquéllos de ayer sean los mismos que hoy pretenden frenar la consolidación de un Proyecto que lucha por la defensa de los derechos humanos, la redistribución del ingreso, la recuperación del sistema previsional argentino, la sanción de una ley de servicios de comunicación audiovisual de la democracia, y en definitiva, un Proyecto que lucha por una Argentina más justa y equitativa que nos contenga a todos (cláusulas 18-23)

Quizás -porque en realidad ni ellos pueden explicar claramente las ideas que los acercan y aquellas que los alejan- tengan que ver con "una mirada de la política nacional, una mirada sobre la propia estrategia ...”(cláusulas 33-39)

¿A la democracia la fortalecemos con más democracia? (cláusula 45)

Resulta por demás llamativo que, los portavoces del discurso apocalíptico junto a los demócratas representantes de las cámaras patronales sojeras, defensores a ultranza del libre juego de las reglas de la democracia, decidan que esta forma de gobierno no les conviene y dejen entonces para otro momento la posibilidad de someterse al voto popular (cláusulas 46-50) 
Fragmento

Discurso

Te defendés con la libertad de prensa (cláusula 91)

Editorial del

Y se pelea por (cláusula 138)

22 de abril

Nuestra fuerza es la militancia (cláusula 157)

ed 2009

Defender un futuro para los argentinos (cláusula 160)

Pegás como partido político (cláusula 90)

Sencillamente queremos que a los argentinos no nos pase más el no te metas, el mirar para el costado mientras secuestran, torturan, asesinan y desaparecen miles de compatriotas, o se celebra el genocidio del mercado como en los '90 (cláusulas 99-106)

Y fue en ese momento cuando a través de tus cívicos voceros de ocasión operaste sensaciones infundadas tan nocivas para nuestra democracia tales como fraude, manipulación, coacción, y otras tantas barbaridades (cláusula 116)

Gratificarte, en un concurso de insultos (cláusula 139)

Se encarnara desde este Proyecto una férrea defensa de los derechos humanos (cláusula 31)

Editorial del

Un Proyecto de país que lucha para no dar marcha atrás y volver a 25 de mayo de 2009 aquellos días que provocaron las consecuencias más tristes de nuestra historia (cláusulas 32-37)

Otrora comandada por el compañero Néstor Kirchner (cláusula 41)

Seguiremos luchando por un modelo de país con igualdad, verdad, memoria y justicia (cláusula 67)

Por los compañeros que lucharon, por los que luchan y por los que podrán enorgullecerse de las conquistas alcanzadas

(cláusulas 68-72)

Dar la pelea en todos los frentes (cláusula 78)

Editorial del

Donde hay todavía muchos argentinos que nos resistimos a la privatización 23 de junio de la conciencia que los monopolios comunicativos ejercen (cláusulas 94-96) de 2009

Nunca bombardeamos con los medios la autoestima de los argentinos (cláusula 105)

El 28 vamos a reventar las urnas (cláusula 131) 
Fragmento

Discurso

Hoy lucha, contra infinidad de intereses (cláusula 14)

Editorial

La virulencia en los ataques mediáticos no hace más que negar su independencia a la hora de (cláusula 24)

Los Medios de comunicación tradicionales de la Argentina salieron fortalecidos luego de la última dictadura (cláusula 27)

Proteger los intereses a (cláusula 30)

Todo esto se desarrolla en medio del más virulento ataque mediático (cláusula 53)

A eso los habían acostumbrado aquellos políticos que de rodillas y basta cuerpo a tierra, se sumieron a la dictadura del mercado (cláusulas 60-61)

Fue el garante del status quo [sic] y la protección de los negocios de aquellos (cláusula 72)

Le pusieron un cepo a la democracia (cláusula 74)

La voluntad política de este Proyecto, se lleva puestos uno a uno los tabúes (cláusula 81)

En la vereda de enfrente hay poderosos intereses que acechan nuestra democracia (cláusulas 86-87)

"En los momentos decisivos, una juventud maravillosa supo oponerse, con la decisión y el coraje de las más vibrantes epopeyas nacionales, a la pasión ciega y enfermiza de una oligarquía delirante" (cláusula 91)

Enfrentar esta nueva UTE opositora (cláusula 103)

Muestra de forma nítida los dos modelos en pugna (cláusula 9)

Editorial

del 30 de

No es casualidad que estos personajes oscuros aparezcan justo ahora con este tipo de iniciativas contra los jóvenes (cláusula 68)

Los jóvenes estamos muy conscientes de nuestros derechos y convencidos de conquistarlos (cláusulas 72-73)

Aquel modelo condenó a millones de pibes a la exclusión y a la desesperanza (cláusula 13)

Los que destruyeron la Argentina durante décadas (cláusula 21)

La oposición quiere encerrarlos en los cuarteles (cláusula 37)

Los quieren encerrados, escondidos, presos, apartados del resto

(cláusulas 43-46)

En los 90 nos sacaban el trabajo, la educación y nos daban palos y represión (cláusulas 74-75)

Por cada intento de agresión, discriminación, estigmatización, como este absurdo proyecto de ley, que recibamos los jóvenes, contestaremos con el doble de participación, el doble de discusión, el doble de organización y el doble de creatividad y alegría (cláusulas 84-85) 


\begin{tabular}{ll}
\hline Fragmento & Discurso \\
\hline $\begin{array}{l}\text { Mi único béroe en este lío (cláusula 1) } \\
\text { Nos invade un profundo dolor ante la ausencia de Néstor (cláusula 26) }\end{array}$ & $\begin{array}{l}2 \text { de } \\
\text { noviem- } \\
\text { bre de 2010 }\end{array}$ \\
$\begin{array}{l}\text { Informal, políticamente incorrecto, transgresor, eternamente joven, } \\
\text { caprichoso, un verdadero defensor de la Causa (cláusula 41) }\end{array}$ & \\
NÉSTOR tomó como bandera (cláusula 45) & \\
\hline
\end{tabular}

\subsection{Estructuras temporales y espaciales dislocadas}

Continuando con el estudio de los dos ejes mencionados en el apartado anterior — sincronía y diacronía-, detectamos, en el corpus, una insistencia en la utilización de estructuras temporales y espaciales dislocadas a la izquierda de la cláusula. Consideramos que las estructuras temporales corresponden a la distinción en diacronía y las estructuras espaciales a la estructura en sincronía. Así, las primeras sirven para hacer hincapié en el cambio radical en la historia de Argentina antes y después del kirchnerismo; mientras que las segundas permiten establecer la existencia de una amenaza dentro de la misma temporalidad. Ambas estructuras - temporales y espaciales- se conectan con el discurso fundacional en tanto plantean al kirchnerismo como una ruptura con el pasado y comienzo de una nueva tradición política, por un lado, y disputa por el territorio, por el otro.

Ejemplo de dislocaciones a la izquierda que marcan la oposición antes del 2003 vs. después del 2003:

1. En los 90 nos sacaban el trabajo, la educación y nos daban palos y represión. Ahora quieren volver a hacer lo mismo. (30.09.2010f)

Ejemplos de dislocaciones a la izquierda que marcan la oposición entre Kirchnerismo y oposición política:

2. En la oposición critican todo, en el gobierno no hacen nada. (21.08.2009n)

3. En la vereda de enfrente hay poderosos intereses que acechan nuestra democracia, pero aquí estaremos tratando de honrar aquello que dijera el Tío Cámpora el 25 de mayo de 1973. (28.12.2009q)

Sin embargo, el contraste no siempre aparece explícito: 
4. Hoy la Patria vuelve transitar una etapa de reencuentros. (17.11.2008a) (Presupone que hubo una etapa de encuentros seguida de una de enfrentamientos).

5. Durante décadas se construyó un modelo de entrega. (13.04.2009e) (Permite inferir que no se mantiene en el presente)

6. Aquí, en la Argentina terrenal, quedó un pueblo despierto conducido por la mejor presidenta. (27.11.2010h) (Presupone que hay otra Argentina).

Consideramos que, en el discurso de la agrupación La Cámpora, las estructuras temporales y espaciales dislocadas a la izquierda de la cláusula se utilizan como focos contrastivos (Gundel y Fretheim 2006; Prince 1992) que buscan atraer la atención del hablante hacia esos constituyentes y contraponer dos ámbitos (reales o simbólicos) o dos tiempos, aparezcan explícitos los dos elementos a contrastar o no. En los casos en que aparece explicitado solo un elemento de la dicotomía, el otro puede ser repuesto fácilmente por el lector.

Una vez analizada, en el corpus de editoriales de La Cámpora, la totalidad de dislocaciones a la izquierda de expresiones temporales y espaciales, los datos arrojados muestran una gran desproporción entre el hincapié que se hace en la diferencia temporal y la diferencia espacial.

Tabla 3. Expresiones dislocadas a la izquierda

\begin{tabular}{|l|c|c|}
\hline $\begin{array}{l}\text { Totalidad de expresiones temporoespaciales } \\
\text { dislocadas a la izquierda }\end{array}$ & 132 & $100 \%$ \\
\hline Expresiones espaciales & 23 & $17,42 \%$ \\
\hline Expresiones temporales & 109 & $82,58 \%$ \\
\hline
\end{tabular}

Si nos centramos en la función de las dislocaciones temporales, podemos observar una clara preponderancia de los elementos que marcan simultaneidad con el presente de la enunciación - y, especialmente, del adverbio "hoy"- por sobre todo el resto de las expresiones temporales (ver tabla 4). Durante el análisis, las expresiones fueron divididas según se refieren a un momento anterior, 
simultáneo o posterior con respecto a la enunciación. También se contemplaron por separado categorías que remiten al pasado, pero que conservan su efecto en el presente enunciativo y las que marcan frecuencia. A continuación, presentamos los valores y porcentajes correspondientes a cada categoría temporal.

\section{Tabla 4. Expresiones dislocadas temporales a la izquierda}

\begin{tabular}{|l|l|l|}
\hline Expresiones temporales & 109 & $100 \%$ \\
\hline $\begin{array}{l}\text { Adverbios que marcan simultaneidad con momento de la } \\
\text { enunciación ("ya", "ahora", "hoy", "aún”) }\end{array}$ & 52 & $47,7 \%$ \\
\hline $\begin{array}{l}\text { Resto de expresiones temporales de simultaneidad, } \\
\text { anterioridad o posterioridad con respecto al momento de } \\
\text { enunciación }\end{array}$ & 57 & $52,3 \%$ \\
\hline
\end{tabular}

Tabla 5. Expresiones dislocadas temporales a la izquierda (desglosada)

\begin{tabular}{|l|c|c|}
\hline Expresiones temporales & 109 & $100 \%$ \\
\hline $\begin{array}{l}\text { Expresiones deícticas referidas al presente de la } \\
\text { enunciación }\end{array}$ & 52 & $47,7 \%$ \\
\hline Subtotales & 34 & $31,2 \%$ \\
\hline Hoy & 8 & $7,3 \%$ \\
\hline Ahora & 6 & $5,5 \%$ \\
\hline Ya & 4 & $3,7 \%$ \\
\hline Aún & 1 & $0,9 \%$ \\
\hline Otros & 1 & $0,9 \%$ \\
\hline Expresiones no deícticas referidas al presente & 7 & $6,4 \%$ \\
\hline $\begin{array}{l}\text { Expresiones referidas al pasado que implican } \\
\text { continuidad en el presente }\end{array}$ & 7 & $6,4 \%$ \\
\hline Expresiones deícticas referidas al pasado & 25 & $23 \%$ \\
\hline Expresiones no deícticas referidas al pasado & 12 & $11 \%$ \\
\hline Expresiones que indican frecuencia & 1 & $0,9 \%$ \\
\hline Expresiones deícticas referidas al futuro & 3 & $2,8 \%$ \\
\hline Expresiones no deícticas referidas al futuro
\end{tabular}


Como mencionamos anteriormente, de acuerdo con la tabla 3 , los focos que marcan una diferencia temporal tienen una presencia mucho mayor que las dislocaciones espaciales. A su vez, de las tablas 4 y 5 , observamos una clara preponderancia de los elementos que marcan simultaneidad con el presente de la enunciación -y, especialmente, del adverbio "hoy"- por sobre todo el resto de las expresiones temporales. Este foco temporal tiene por función resaltar la trascendencia histórica del tiempo presente con respecto a un pasado que fue combatido y derrotado (matiz épico de construcción de una heroicidad en el cumplimiento de una tarea elevada y derrota de los enemigos). Recordemos que el discurso épico no habla de una batalla entre dos territorios, sino de una disputa por la recuperación del territorio perdido. En este sentido, la oposición ayer/hoy se puede interpretar como la recuperación del poder luego de la dictadura militar de los años 70 y del neoliberalismo de los años 90 .

A continuación, presentamos - por ser cuantitativamente las más relevantes- todas las expresiones focalizadas correspondientes al presente de enunciación:

\section{Tabla 6. Expresiones deícticas referidas al presente de la enunciación}

\begin{tabular}{|l|l|}
\hline \multicolumn{2}{|l|}{ Expresiones deícticas referidas al presente de la enunciación } \\
\hline Hoy, desde hace 36 años, se vive en nuestro país & $\begin{array}{l}17 \text { de noviembre de } \\
2008\end{array}$ \\
\hline Hoy la Patria vuelve transitar una etapa de reencuentros. & $\begin{array}{l}17 \text { de noviembre de } \\
2008\end{array}$ \\
\hline Hoy 20 de noviembre es el Día de la Soberanía & $\begin{array}{l}20 \text { de noviembre de } \\
2008\end{array}$ \\
\hline Ya no lavan platos & $\begin{array}{l}14 \text { de marzo de } \\
2009\end{array}$ \\
\hline Hoy más que nunca & 13 de abril de 2009 \\
\hline $\begin{array}{l}\text { Hoy más que nunca tenemos que ser conscientes que la } \\
\text { lucha es permanente }\end{array}$ & 13 de abril de 2009 \\
\hline $\begin{array}{l}\text { Hoy más que nunca tenemos que hacer frente a nuevos } \\
\text { desafíos y dificultades pero con las convicciones de siempre }\end{array}$ & 13 de abril de 2009 \\
\hline
\end{tabular}




\begin{tabular}{|l|l|}
\hline \multicolumn{2}{|l|}{ Expresiones deícticas referidas al presente de la enunciación } \\
\hline $\begin{array}{l}\text { Hoy más que nunca estamos orgullosos del camino iniciado } \\
\text { el } 25 \text { de mayo de } 2003\end{array}$ & 13 de abril de 2009 \\
\hline $\begin{array}{l}\text { Hoy más que nunca tenemos la certeza que era el camino } \\
\text { correcto, a pesar de las “célebres” voces }\end{array}$ & 13 de abril de 2009 \\
\hline Hoy pretender frenar la consolidación de un Proyecto... & 13 de abril de 2009 \\
\hline $\begin{array}{l}\text { Aunque ahora parece que esta Nueva Alianza forzada de } \\
\text { cara a las elecciones legislativas tiene “algunos problemas” }\end{array}$ & 13 de abril de 2009 \\
\hline Hoy padece la ciudad & 15 de abril de 2009 \\
\hline $\begin{array}{l}\text { Ahora tenemos la oportunidad de } \\
\text { comenzar un camino distinto }\end{array}$ & 15 de abril de 2009 \\
\hline Mientras hoy llamás a Alfonsín Padre de la Democracia... & 22 de abril de 2009 \\
\hline Hoy podemos expresar con la plena convicción & 22 de abril de 2009 \\
\hline $\begin{array}{l}\text { Hoy como cada 25 de mayo desde hace seis años, tratamos } \\
\text { de recordar aquel mediodía de 2003, la imagen de un } \\
\text { hombre sencillo }\end{array}$ & 25 de mayo de 2009 \\
\hline Hoy estamos orgullosos de... & 25 de mayo de 2009 \\
\hline Hoy liderada por nuestra compañera Cristina & 25 de mayo de 2009 \\
\hline Hoy tenemos la gran oportunidad de & 25 de mayo de 2009 \\
\hline Aún no termina de escribirse & 25 de mayo de 2009 \\
\hline $\begin{array}{l}\text { Hoy Aerolíneas pierde menos dinero y tiene más } \\
\text { frecuencias aéreas }\end{array}$ & 23 de junio de 2009 \\
\hline $\begin{array}{l}\text { Hoy Aerolíneas pierde menos dinero pero empezó a } \\
\text { comprar aviones, }\end{array}$ & 23 de junio de 2009 \\
\hline Ya no improvisamos & 9 de julio de 2009 \\
\hline $\begin{array}{l}\text { Hoy, más que nunca, acompanemos a nuestra Presidenta } \\
\text { coraje, nuestra companera Cristina }\end{array}$ & 9 de julio de 2009 \\
\hline $\begin{array}{l}\text { Hoy, más que nunca, respaldemos a nuestro conductor, a } \\
\text { nuestro compañero Néstor }\end{array}$ & 9 de julio de 2009 \\
\hline $\begin{array}{l}\text { Hoy, más que nunca, construyamos para nuestro } \\
\text { movimiento el lugar que se merece en la historia y en el } \\
\text { corazón del Pueblo }\end{array}$ & 9 de julio de 2009 \\
\hline $\begin{array}{l}\text { Ya era una trinchera popular contra los monopolios de ayer } \\
\text { y de hoy }\end{array}$ & 21 de agosto de \\
\hline $\begin{array}{l}\text { Ahora no llevaba la pelota, pero sonreía feliz porque la } \\
\text { pelota iba a ser de todos }\end{array}$ & 21 de agosto de \\
2009 \\
\hline
\end{tabular}




\begin{tabular}{|c|c|}
\hline \multicolumn{2}{|l|}{ Expresiones deícticas referidas al presente de la enunciación } \\
\hline Ya se escucha el eco de los refutadores de leyendas & $\begin{array}{l}21 \text { de agosto de } \\
2009\end{array}$ \\
\hline $\begin{array}{l}\text { Hoy la } 10 \text { la lleva la Compañera Coraje y al lado estamos } \\
\text { todos }\end{array}$ & $\begin{array}{l}21 \text { de agosto de } \\
2009\end{array}$ \\
\hline $\begin{array}{l}\text { Hoy podemos decir que nuestra democracia se encuentra } \\
\text { en un momento crucial. }\end{array}$ & $\begin{array}{l}28 \text { de diciembre de } \\
2009\end{array}$ \\
\hline Hoy lucha, contra infinidad de intereses, por & $\begin{array}{l}28 \text { de diciembre de } \\
2009\end{array}$ \\
\hline Aún nos cuesta apreciar en toda su dimensión. & $\begin{array}{l}28 \text { de diciembre de } \\
2009\end{array}$ \\
\hline Hoy nos encontramos frente a un momento maravilloso & $\begin{array}{l}28 \text { de diciembre de } \\
2009\end{array}$ \\
\hline Hoy corren por izquierda al gobierno popular, & 29 de julio de 2010 \\
\hline Hoy, en lugar de decir "me equivoqué, dice que & 29 de julio de 2010 \\
\hline Ahora más que nunca & $\begin{array}{l}12 \text { de septiembre de } \\
2010\end{array}$ \\
\hline Hoy los jóvenes estamos contentos y tranquilos: & $\begin{array}{l}12 \text { de septiembre de } \\
2010\end{array}$ \\
\hline Hoy los jóvenes seguimos contentos, & $\begin{array}{l}12 \text { de septiembre de } \\
2010\end{array}$ \\
\hline Hoy domestican a la oposición & $\begin{array}{l}12 \text { de septiembre de } \\
2010\end{array}$ \\
\hline $\begin{array}{l}\text { Ahora pretenden que los jóvenes se inserten en la "sociedad } \\
\text { civil” justo con los militares }\end{array}$ & $\begin{array}{l}30 \text { de septiembre de } \\
2010\end{array}$ \\
\hline Ahora quieren volver a hacer lo mismo & $\begin{array}{l}30 \text { de septiembre de } \\
2010\end{array}$ \\
\hline Hoy queremos decirte que & $\begin{array}{l}2 \text { de noviembre de } \\
2010\end{array}$ \\
\hline Ya lo dijimos antes & $\begin{array}{l}2 \text { de noviembre de } \\
2010\end{array}$ \\
\hline Hoy más que nunca: ¡GRACIAS NÉSTOR! & $\begin{array}{l}2 \text { de noviembre de } \\
2010\end{array}$ \\
\hline Hoy más que nunca: ¡FUERZA CRISTINA! & $\begin{array}{l}2 \text { de noviembre de } \\
2010\end{array}$ \\
\hline Ya es un recontra lugar común decir & $\begin{array}{l}27 \text { de noviembre de } \\
2010\end{array}$ \\
\hline Y sin embargo ahora son parte de nuestra realidad. & $\begin{array}{l}27 \text { de noviembre de } \\
2010\end{array}$ \\
\hline
\end{tabular}




\begin{tabular}{|l|l|}
\hline Expresiones deícticas referidas al presente de la enunciación \\
\hline Ahora de pronto nos critican porque nos volvió a interesar & $\begin{array}{l}27 \text { de noviembre de } \\
2010\end{array}$ \\
\hline Aún causa estupor & $\begin{array}{l}11 \text { de febrero de } \\
2011\end{array}$ \\
\hline $\begin{array}{l}\text { A esta altura de los acontecimientos ¿Alguien puede creer, } \\
\text { verdaderamente, que la demonización de los sectores }\end{array}$ & $\begin{array}{l}11 \text { de febrero de } \\
2011\end{array}$ \\
\hline $\begin{array}{l}\text { Aún pugnan contra décadas de oprobio, aquellos jóvenes } \\
\text { que no vieron a sus padres trabajar por la fría combinación } \\
\text { de tecnócratas y cipayos, sean los culpables de algo en esta } \\
\text { Argentina? }\end{array}$ & $\begin{array}{l}11 \text { de febrero de } \\
2011\end{array}$ \\
\hline Hoy denigran retrospectivamente al “Tío” a los efectos de & 11 de marzo de \\
\hline
\end{tabular}

Consideramos que tanto la construcción de enemigos referidos al pasado (tabla 1) como la superabundancia de las estructuras temporales que diferencian entre ayer/hoy — con hincapié en la excepcionalidad del momento histórico actual- corresponden a las características descriptas en el apartado de discurso fundacional $\mathrm{y}$ que algunos investigadores del kirchnerismo han denominado pasado denostado (Montero 2012) o rechazado (Buisán, Maizels y Salerno 2013). El carácter fundacional del discurso kirchnerista se encuentra en que nombra ese pasado, lo demoniza, lo clausura y abre un nuevo ciclo (Montero 2012: 85). Así, vemos una ruptura total con el pasado reciente donde el kirchnerismo se presenta como su completo opuesto y como la salvación con respecto a una situación descripta como catastrófica.

Este recorrido se puede observar a partir de las dislocaciones a la izquierda, que presentan - explícitamente en algunos casos- el pasado denostado, su definición temporal, su condena y su contraposición con el presente. La oposición entre antes y después de la llegada del kirchnerismo al poder resalta que se trata de dos Argentinas diferentes y que el actual gobierno representa la llegada de un cambio fundamental y la solución de todos los problemas del país. En los casos en que ese pasado no aparece expresado de forma explícita, la insistencia en el "hoy” y el “ahora” marcan la 
excepcionalidad del presente kirchnerista y dejan implícita la contraposición, la cual, sin embargo, puede ser fácilmente recuperada por el lector. Lo mismo sucede con la construcción "hoy más que nunca” y su variante "ahora más que nunca”. Ambas dan cuenta de la intensidad del momento histórico presente y de la relevancia del llamado a la acción.

\section{Consideraciones finales}

En este trabajo, analizamos la ocurrencia reiterada, en el discurso de la agrupación política La Cámpora, de adversarios construidos como enemigos, por un lado, y de focos temporales y espaciales dislocados a la izquierda, por el otro. Consideramos que su utilización se corresponde con una construcción del discurso de la agrupación como fundacional (Zoppi Fontana 1993; Charaudeau 2009).

Con respecto al primer eje de análisis, la conceptualización de la política a partir del sistema metafórico bélico habilita la construcción del adversario político en términos de un enemigo que hay que derrotar. Los enemigos son un elemento casi omnipresente en el discurso de La Cámpora, que construye sus editoriales en oposición a un otro, ya sea político, empresario, grupo económico, periodista o algún sector social. La oposición puede estar construida diacrónicamente (antes/después del kirchnerismo), donde se diferencia al proyecto kirchnerista del pasado derrotado, o en sincronía, donde se muestran los enemigos que, aunque debilitados, buscan recuperar el poder perdido. Sin embargo, encontramos una prevalencia de enemigos actuales por sobre los enemigos del pasado.

Con respecto al segundo eje de análisis, la construcción de enemigos -y su oposición al kirchnerismo- se encuentra reforzada en el discurso de La Cámpora por la utilización de adjuntos temporales y espaciales que se encuentran en una posición focal dentro de la cláusula. Este recurso se emplea con dos funciones estrechamente vinculadas con el discurso fundacional: 1) los adjuntos temporales enfatizan la magnitud del cambio en el país entre antes y después de la llegada del kirchnerismo al gobierno, 2) los adjuntos espa- 
ciales marcan la disputa por el territorio entre el kirchnerismo y los enemigos que aún prevalecen y que constituyen una amenaza para dicho proyecto político. Estos enemigos pondrían en riesgo los logros obtenidos por el actual gobierno y, por lo tanto, representan la razón para continuar con la militancia en defensa del kirchnerismo.

Detectamos una predominancia de las dislocaciones referidas al presente de la enunciación, especialmente del adverbio "hoy". Consideramos que la repetición de esta estructura, junto con la de otros adverbios que también suponen simultaneidad con la enunciación, refuerza el carácter fundacional del discurso militante kirchnerista. Así, el foco contrastivo resalta la trascendencia histórica del tiempo presente con respecto a un pasado que fue combatido y derrotado. En este sentido, la oposición ayer/hoy permite señalar la diferencia de las condiciones del país antes y después de la llegada del kirchnerismo que funcionaría como la solución a los problemas del país. Por su parte, los adjuntos espaciales indican la situación de acecho que vive el kirchnerismo.

En resumen, consideramos que la oposición entre los resultados de ambos ejes de análisis (prevalencia de enemigos actuales por sobre enemigos pasados y preponderancia de estructuras temporales que diferencian un antes y un después en la historia Argentina frente a las estructuras espaciales) se puede interpretar de la siguiente manera:

1. La oposición actual se codifica de forma más explícita nombrando, describiendo o calificando al otro, considerado como un enemigo y una amenaza concreta en el presente.

2. La oposición con el pasado se representa de una forma recurrente, pero más difusa, en tanto se muestra el contrapunto entre ambas temporalidades, pero no se insiste de forma explícita en quiénes son los actores sociales que corresponden al pasado derrotado.

De cualquier forma, ambos recursos se complementan en su función fundacional del discurso de La Cámpora, mostrando el corte que supuso la llegada de Kirchner al poder y las constantes 
amenazas que acechan y que deben sortear para concretar/profundizar el proyecto. Por ello, consideramos que la construcción de un discurso fundacional permite establecer la necesidad de una militancia juvenil que apoye el proyecto kirchnerista y se convierta en una defensa contra la amenaza que supone, para las mejoras conseguidas por dicho gobierno, la reminiscencia de algunos enemigos del pasado. La insistencia en los cambios conseguidos y la presencia de la amenaza son necesarias para lograr que los jóvenes entiendan la importancia y urgencia de participar en política.

\section{Corpus}

La CÁmPORA [LC]

2008a “1972 - 17 de noviembre - 2008”. La Cámpora. 17 de noviembre Consultado: 2 marzo de 2012. <http: //www. lacampora.org>.

2008b “En el Día de la Soberanía: Chau a las AFJP!”. La Cámpora. 20 de noviembre. Consultado: 2 marzo de 2012. <http: // www.lacampora.org $>$.

2009a "Nuestro candidato es el proyecto". La Cámpora. 14 de marzo. Consultado: 2 marzo de 2012. <http: //www.lacampora.org>.

2009b "Redistribución SI, Teoría del derrame NO”. La Cámpora. 20 de marzo. Consultado: 2 marzo de 2012. <http: //www. lacampora.org $>$.

2009c “Cris Pasión”. La Cámpora. 5 de abril. Consultado: 2 marzo de 2012. <http: //www.lacampora.org>.

2009d "La letra con monopolio entra". La Cámpora. 7 de abril. Consultado: 2 marzo de 2012. <http: //www.lacampora.org>.

2009e "Hoy más que nunca". La Cámpora. 13 de abril. Consultado: 2 marzo de 2012. <http: //www.lacampora.org>.

$2009 \mathrm{f}$ ¿Qué es ser progresista?”. La Cámpora. 15 de abril. Consultado: 2 marzo de 2012. <http: //www.lacampora.org>.

2009g "Para Oscurín un Rivotril”. La Cámpora. 22 de abril. Consultado: 2 marzo de 2012. <http: //www.lacampora.org>.

2009h "30 minutos en un semáforo o 30 años de miseria”. La Cámpora. 1 de mayo. Consultado: 2 marzo de 2012. <http: //www. lacampora.org>. 
2009i “Todo con el 22\%”. La Cámpora. 25 de mayo. Consultado: 2 marzo de 2012. <http: //www.lacampora.org>.

2009j "La censura que no es censura". La Cámpora. 18 de junio. Consultado: 2 marzo de 2012. <http: //www.lacampora.org>.

2009k “Tienen un Plan”. La Cámpora. 23 de junio. Consultado: 2 marzo de 2012. <http: //www.lacampora.org>.

20091 “A los compañeros de La Cámpora”. La Cámpora. 9 de julio. Consultado: 2 marzo de 2012. <http: //www.lacampora.org>.

2009m "Manso y Adjetivo". La Cámpora. 14 de agosto. Consultado: 2 marzo de 2012. <http: //www.lacampora.org>.

2009n "El proyecto no se mancha". La Cámpora. 21 de agosto. Consultado: 2 marzo de 2012. <http: //www.lacampora.org>.

2009o "Hegemonía K". La Cámpora. 1 de octubre. Consultado: 2 marzo de 2012. <http: //www.lacampora.org $>$.

2009p "De cara al futuro". La Cámpora. 26 de octubre. Consultado: 2 marzo de 2012. <http: //www.lacampora.org>.

2009q “199”. La Cámpora. 29 de diciembre. Consultado: 2 marzo de 2012. <http: //www.lacampora.org>.

2010a "Gato por liebre”. La Cámpora. 4 de marzo. Consultado: 2 marzo de 2012. <http: //www.lacampora.org>.

2010 b “Asusta un poco verte asî”. La Cámpora. 12 de mayo. Consultado: 2 marzo de 2012. <http: //www.lacampora.org >.

2010c "Repudio". La Cámpora. 19 de junio. Consultado: 2 marzo de 2012. <http: //www.lacampora.org>.

$2010 \mathrm{~d}$ "Peronismo puro, kirchnerismo al palo". La Cámpora. 29 de julio. Consultado: 2 marzo de 2012. <http: //www.lacampora.org>.

2010e "Ahora más que nunca". La Cámpora. 12 de septiembre. Consultado: 2 marzo de 2012. <http: //www.lacampora.org>.

$2010 \mathrm{f}$ "Ni servicio, ni cívico, ni voluntario". La Cámpora. 30 de septiembre. Consultado: 2 marzo de 2012. <http: //www. lacampora.org $>$.

$2010 \mathrm{~g}$ "Mi único héroe en este lío". La Cámpora. 2 de noviembre. Consultado: 2 marzo de 2012. <http: //www.lacampora.org>. 2010h "Lágrimas de compromiso". La Cámpora. 27 de noviembre. Consultado: 2 marzo de 2012. <http: //www.lacampora.org>.

2011a “A esta altura...”. La Cámpora. 11 de febrero. Consultado: 2 marzo de 2012. <http: //www.lacampora.org>.

2011b “El nacimiento de La Cámpora”. La Cámpora. 11 de marzo. Consultado: 2 marzo de 2012. <http: //www.lacampora.org>. 
2011c “La Cámpora para nosotros”. La Cámpora. 28 de mayo. Consultado: 2 marzo de 2012. <http: //www.lacampora.org>.

2011d "Mentiras con fecha de vencimiento". La Cámpora. 4 de julio. Consultado: 2 marzo de 2012. <http: //www.lacampora.org>.

\section{Referencias bibliográficas}

BALSA, Javier

2013 Discurso, política y acumulación en el kirchnerismo. Buenos Aires: CCC/Universidad Nacional de Quilmes.

BOWra, Cecil

1961 Heroic Poetry. Londres: Macmillan.

Buisán, Andrés, Ana Maizels y Paula Salerno

2013 'La construcción del 'nosotros' y del 'ellos' en los discursos de Cristina Fernández en el marco de la crisis con el sector agropecuario: democracia y golpismo, pueblo y oligarquía, pasado legitimador y pasado rechazado". En Actas del Coloquio Nacional de la Asociación Latinoamericana de Estudios del Discurso. Ed., Sara Isabel Pérez. Bernal: Universidad Nacional de Quilmes. En prensa.

Campbell, Joseph

[1949] 1972 El héroe de las mil caras. México: Fondo de Cultura Económica.

Charaudeau, Patrick

2009 "Reflexiones para el análisis del discurso populista”. Discurso y Sociedad. 3, 2, 253-279.

CONTE, Gian Biagio

1986 The Rhetoric of Imitation. Genre and Poetic Memory in Virgil and other Poets. London: Cornell University Press.

DagatTi, Mariano

2013 "Contribuciones para una cartografía discursiva del primer kirchnerismo". En Discurso, política y acumulación en el kirchnerismo. Ed., Javier Balsa. Buenos Aires: CCC/Universidad Nacional de Quilmes. 
Flax, Rocío

2014 "La construcción del otro en los discursos de La Cámpora”. Ponencia presentada IX Congreso Latinoamericano de Lingüistica Sistémico-Funcional. Santiago de Chile: Pontificia Universidad Católica de Chile.

2016 "La articulación hegemónica en el discurso de la agrupación La Cámpora”. Revista Mexicana de Sociología. 78, 1, 89-118.

Foucault, Michel

[1969] 2008 La arqueología del saber. Buenos Aires: Siglo XXI.

Guimarães, Eduardo

1993 "Independência e norte". En Discurso fundador: a formação do país e a construção da identidade nacional. Ed., Eni Orlandi. Campinas: Pontes.

Gundel, Jeanette y Thorstein Fretheim

2006 "Topic and Focus". En The Handbook of Pragmatics. Eds., Laurence Horn y Gregory Ward. Oxford: Blackwell, 175-196. https://doi.org/10.1002/9780470756959.ch8

Halliday, Michael

1982 El lenguaje como semiótica social. México: Fondo de Cultura Económica.

Menéndez Pidal, Ramón

1934 Historia y Epopeya (Obras Completas II). Madrid: Centro de Estudios Históricos.

1945 La epopeya castellana a través de la literatura española. Madrid: Espasa-Calpe.

Montero, Ana Soledad

$2012 Y$ al final un día volvimos. Los usos de la memoria en el discurso kirchnerista (2003-2007). Buenos Aires: Prometeo.

Nunes, José Horta

1993 "Manifestos modernistas: a identidade nacional no discurso e na língua”. En Discurso fundador: a formação do país e aconstrução da identidade nacional. Ed., Eni Orlandi. Campinas: Pontes. 
OrLANDI, Eni

1993 "Vao surgindo sentidos". En Discurso Fundador: a formação do país e a construção da identidade nacional. Ed., Eni Orlandi. Campinas: Pontes.

Paquette, Jean-Marcel

1988 Typologie des sources du Moyen Âge occidental. Turnhout: Brepols.

Prince, Ellen

1992 "The ZPG letter: Subjects, Definiteness, and Information Status". En Discourse Description: Diverse Analyses of a Fund Raising Text. Eds., Sandra Thompson y William Mann. Philadelphia: John Benjamins, 295-325.

RAITER, Alejandro

2009 “'Hablo y entiendan': creencias, presuposición e interdiscurso en los actos de Cristina Fernández de Kirchner”. Oralia, 12, 73-96.

2013 “¿Existe una lógica discursiva kirchnerista? Constancias y alternancias”. En Discurso, política y acumulación en el kirchnerismo. Ed. Javier Balsa. Buenos Aires: CCC/Universidad Nacional de Quilmes.

Sigal, Silvia y Eliseo Verón

1986 Perón o muerte: los fundamentos discursivos del fenómeno peronista. Buenos Aires: EUDEBA.

VERÓN, Eliseo

2011 La semiosis social. Fragmento de una teoría de la discursividad. México DF: Gedisa.

Zoppi FonTANa, Mónica

1993 "Sonhando a Pátria: os fundamentos de repetidas fundações". En Discurso fundador: a formação do país e aconstrução da identidade nacional. Ed., Eni Orlandi. Campinas: Pontes, 127149.

Recibido: $11 / 09 / 2015$ Aceptado: 28/09/2017 